\title{
Horizontal Chin Bar
}

\author{
Mehdi Deylami Pour'1, Hamid Karimi ${ }^{2,3}{ }^{*}$, Amir-Hossein Deilami-Pour ${ }^{4}$, \\ Sara Deylami-Pour ${ }^{5}$ \\ ${ }^{1}$ Plastic Surgery Private Practice, Tehran, Iran \\ ${ }^{2}$ Plastic Surgery, Iran University of Medical Sciences, Tehran, Iran \\ ${ }^{3}$ Plastic Surgery Department, Hazrat Fatemeh Hospital, Tehran, Iran \\ ${ }^{4}$ Azad Medical University, Tehran, Iran \\ ${ }^{5}$ Dental School, University of Nevada, Las Vegas, USA \\ Email: karimihamid11@gmail.com, ${ }^{*}$ hamidkarimi1381@yahoo.com
}

Received 10 October 2014; revised 10 November 2014; accepted 3 December 2014

Academic Editor: Bulang Gao, Shanghai Jiao Tong University, China

Copyright (C) 2014 by author and Scientific Research Publishing Inc. This work is licensed under the Creative Commons Attribution International License (CC BY). http://creativecommons.org/licenses/by/4.0/

(c) (i) Open Access

\section{Abstract}

Background: Correction of long face and chin retrusion has a significant effect on facial aesthetic and symmetry. Bimaxillary (Bimax.) Operation has been performed for long face and bimaxillary dentoalveolar protrusion. But bimaxillary surgery cannot address all of complex deformity of mandible. The new technique using horizontal chin bar can treat mandibular dentoalveolar protrusion and chin retrusion in one setting. Objectives: To evaluate the results of mandible segmental osteotomy and jumping genioplasty; To illustrate the versatility and the ease of this procedure and to confirm the good to excellent clinical results obtained with minimal complications. Design: Retrospective study setting, all of the patients of university hospital and private practice who seek medical attention for long face and retruded (and/or deviated) chin were included in the study. Patients and surgeons satisfaction were evaluated. Results: 45 patients, aged 19 - 30 years (mean age, $24 \pm 6$ years) underwent the creation of a horizontal chin bar (4 $-7 \mathrm{~mm}$ wide) as an axis for two opposite bone movement (and a place for fixation) of mandibular dentoalveolar segment and lower chin segment [segmental lower jaw (Kolle's) operation and genioplasty], and/or with concomitant Bimax. operation. The mean chin advancement was 8 mm (4 - 10 mm). Average setback for mandible was $3 \mathrm{~mm}$ ( 2 - $6 \mathrm{~mm}$ ). No bone resorption was identified. No permanent nerve paresthesia was noted. There was one case of the bar fracture due to narrowness of the bar. 37 patients were highly satisfied and 8 were satisfied with the results. There was no dissatisfaction in our patients and surgeons. Conclusion: For long face and retruded chin one of the best treatments is horizotal chin bar method with very good long-term results. EBM: Level IV.

${ }^{*}$ Corresponding author. 


\section{Keywords}

\section{Long Face, Bimaxillary Surgery, Genioplasty, Segmental Osteotomy}

\section{Introduction}

Facial bone deformities have different presentations. One of the very difficult and skill demanding deformities is bimaxillary (Bimax.) dentoalveolar protrusion. These patients usually have a long face and a retruded chin (Figure 1). In the past, bimaxillary deformity was managed with maxillary set back and body osteotomy of mandible after orthodontic management. In fact dental and chin deformity were repaired as one piece 9 . But there may be different deformities of chin and dentoalveolar part.

This type of surgery had two disadvantages:

1) If the whole part goes back, the lower face and jaw would be inappropriately wide;

2) If it goes forward, there would be a step in jaw arch and chin would be wide.

There are many of these patients that have protruded anterior segmental mandible plus retruded chin, so the surgeons have to move the two segments in different directions (Figures 1-3). This is especially true in long face patients (Figure 1). These patients usually have long and retruded chin. And reconstruction of the bimaxillary

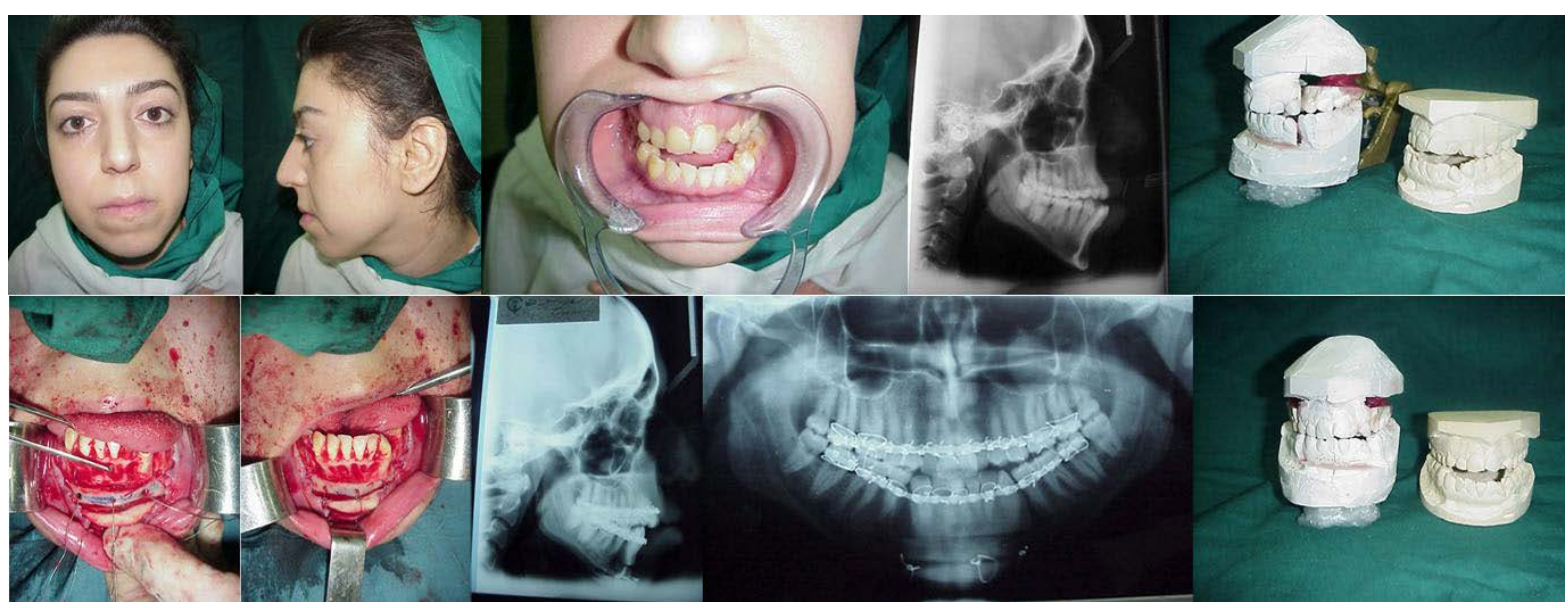

Figure 1. A 28-year-old lady with long face, retruded chin and open bite. The two lower left pictures show horizontal chin bar. Before surgery: Upper two left photos.

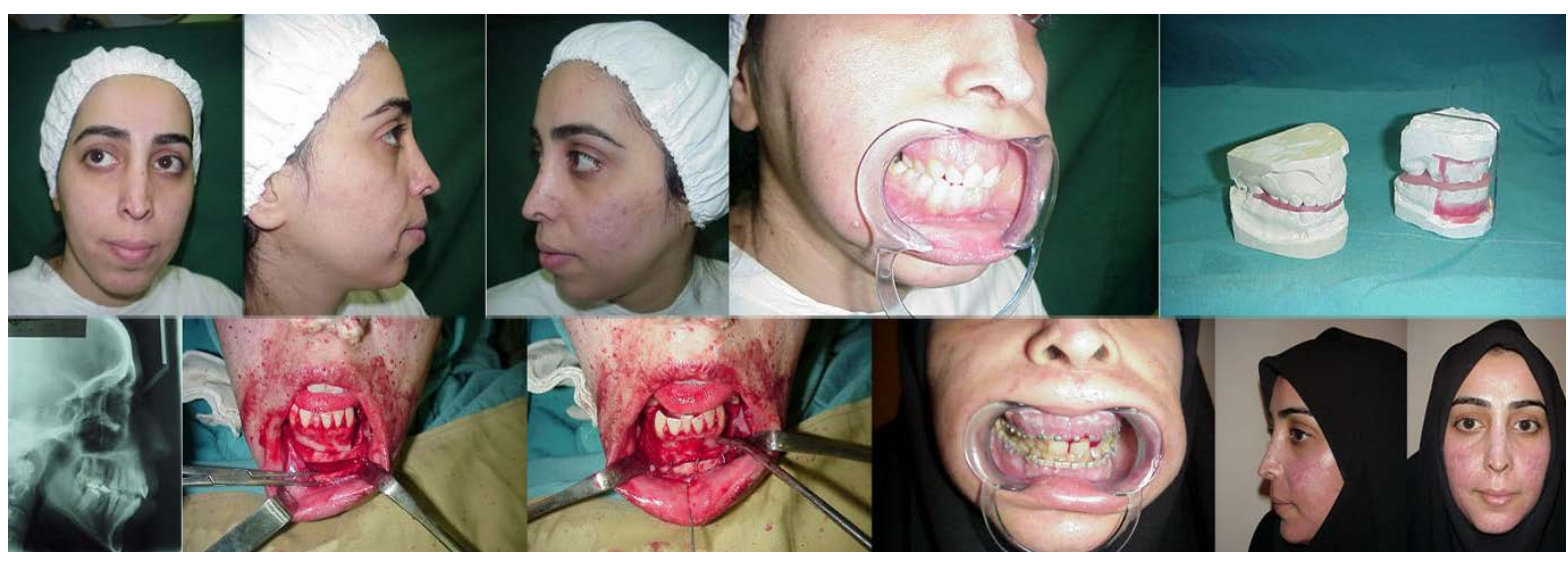

Figure 2. A 32-year-old lady with long face and retruded chin. The right upper most picture shows cast surgery and wafer. Lower row $2^{\text {nd }}$ and $3^{\text {rd }}$ picture from left show horizontal chin bar. Before surgery: Upper left three photos. After surgery: Lower right two photos. 


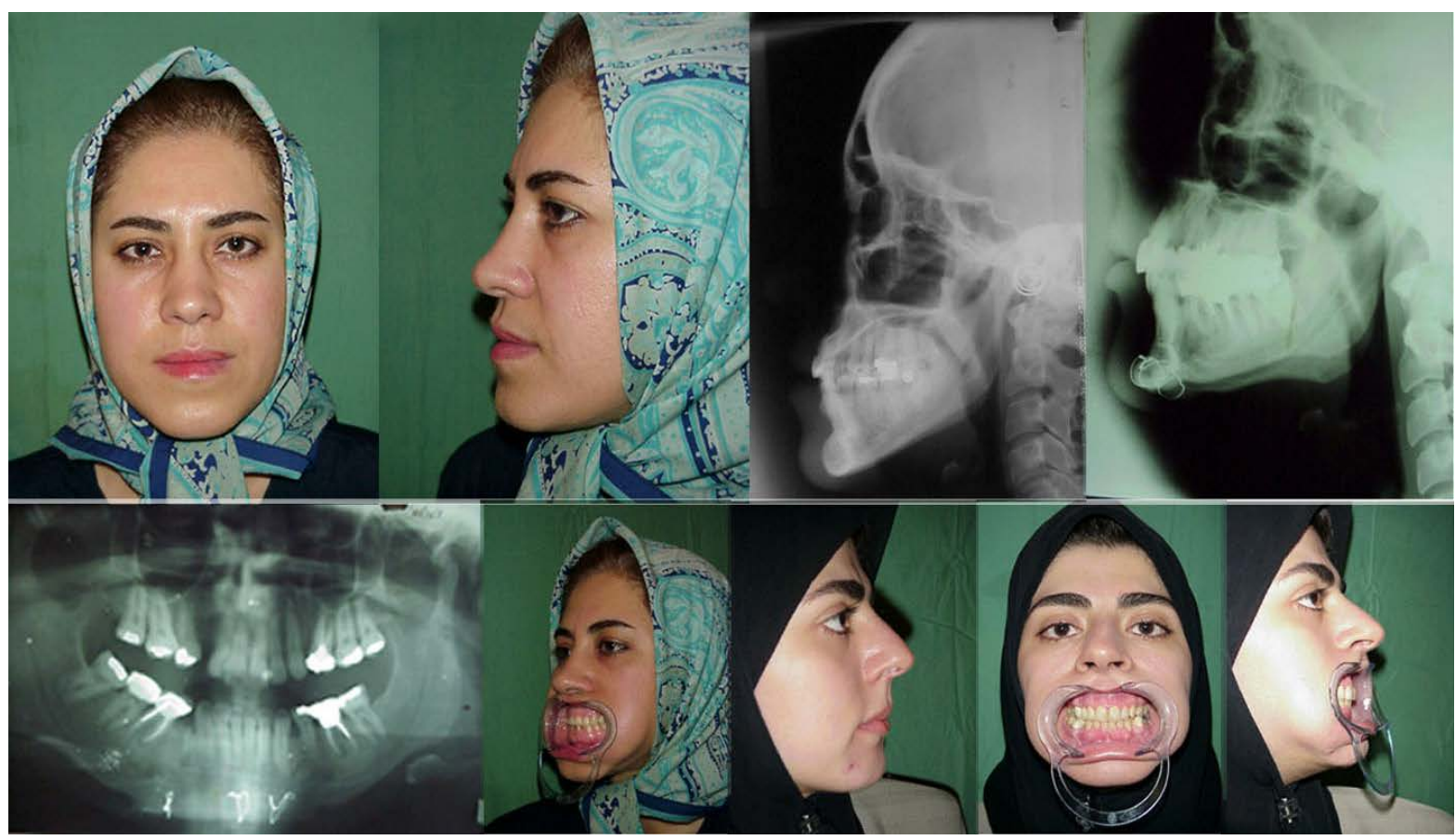

Figure 3. Long face and long chin. Before surgery: Upper left two photos. After surgery: Lower right three photos.

dento-protrusion would produce longer face. In these patients only sagital splitting osteotomy or mandibular body osteotomy cannot solve the problem completely. Therefore some other retouching and complimentary surgeries may be needed afterward. Also these methods cannot correct the chin problem at the same time [2], [3], [7], [8], [10]. And reconstruction of chin is needed during the first surgery. We have a new solution for this problem!

\section{Surgical Technique}

In this method, after orthodontic treatment, by producing a horizontal segmental mandibular bar in the chin region, we treat the protrusion of dentoalveolar part with segmental osteotomy.

So a horizontal middle chin bar will be produced in the anterior part of mandible (Figure 4). This bar is 4 - 7 millimeter wide and with using this bar, the deformity of chin will be treated easily at the same time (whether protrusion, retrusion, even shortness or deviation if necessary) (Figures 1-3).

With this method, the continuity of jaw in coronal plane will be stable. And there would be no widening of face or jaw, and there would be no malocclusion of teeth or any step in dental arch.

Setback of lower jaw will be done by removal of first premolar teeth and dentoalveolar setback will be done and will be fixed by an arch bar only. In the inferior part of horizontal bar, genioplasty (reduction or augmentation) according to patient skeletal deformity will be done. The chin part will be fixed in three points to the horizontal bar by wire (\#24 - \#30), or only screws or plate and screws (Figure 1(h)). But fixation with mini-plate surely would increase the risk of dental root injury.

This horizontal bar is located anterior to the mental nerve, so there is no risk of trauma to the nerve.

Approach to the operating site is from inside of mouth and with gingival incision. Degloving of soft tissue will be done anteriorly and posterior soft tissue pedicle of chin bone will remain intact. In this way vascularity of chin bone will be saved. In most of patients, the chin would need reduction, and there would be no need of bone graft even in case of chin augmentation. In some cases, jumping genioplasty by the rate of $1 / 3$ to $2 / 3$ can be done and even the jumping part can be placed over the horizontal bar and fixed to it.

\section{Material \& Methods}

In this study we were to evaluate the results of the new technique of using horizontal chin bar in our patients.

During more than 12 years all of the patients with bimax deformity and long face were evaluated. Surgical 


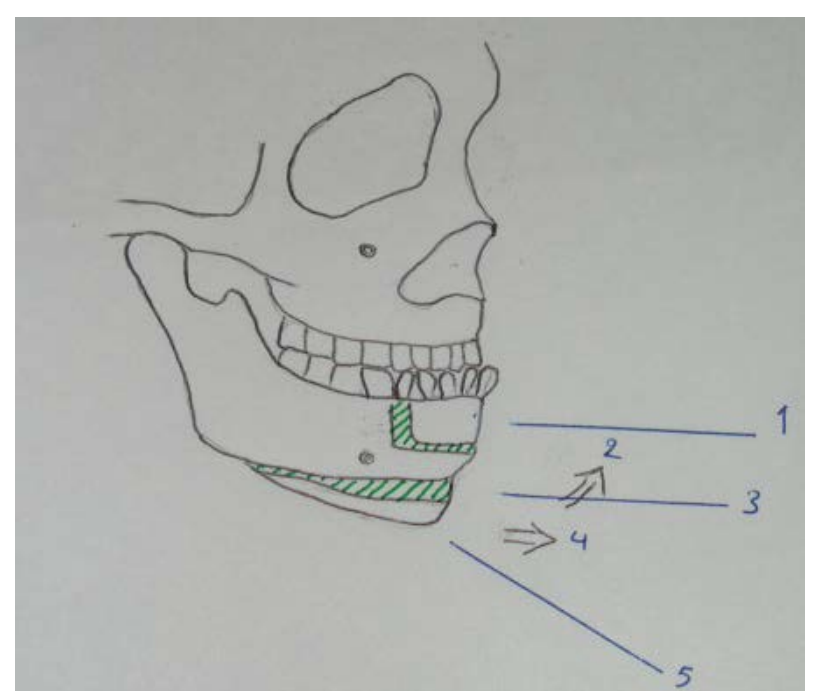

Figure 4. Schematic representation of surgical technique. 1) Mandibular segmental osteotomy; 2) Jumping genioplasty; 3) Horizontal chin bar; 4) Advanced genioplasty; 5) Retruded chin.

method was "bimaxillary segmental setback" or "segmental osteotomy of mandible and le fort I for maxillary impaction of upper jaw". Most of the patients had chin reduction and needed anterior movement of chin or jumping genioplasty [1]. Demographic data were collected for all of our patients. Skull X-rays, Cephalograms and dental cast were taken for each patient. Cast surgeries were done before each operation for evaluation of results and for construction of interdental wafer. All of patients were included in this study. Our technique, horizontal chin bar, were performed for all of our patients. Height of horizontal bar was 4 - 7 millimeter. Photographs before and in several sessions after operation were undertaken to compare the results. Casts and X-rays and cephalograms at least twice in 12 and 24 months after surgery were taken. And used for evaluation of bone resorption and relapse [2].

Mean chin advancement and soft tissue advancement and mean dentoalveolar setback of mandible were calculated. Stability and occlusion were evaluated on standardized X-rays and dental casts.

Satisfaction of patients and surgeons were classified as: excellent, good, moderate, fair. All of the results were analyzed with SPSS 16 software and $p$ value less than $5 \%$ was considered significant.

\section{Results}

In this study, during more than 12 years, we had 45 patients. All of them with prognatism, long face and retruded chin (Figure 5, Figure 6). 34 (84.5\%) were female and 11 (15.5\%) male. The mean age of patients was 24 years (from 18 to 30). Only one patient was smoker.

The mean chin advancement was $8 \mathrm{~mm}(4-10 \mathrm{~mm})$ and soft tissue advancement was 3 - $9 \mathrm{~mm}$. Average setback for mandible was $3 \mathrm{~mm}$ (2 - $6 \mathrm{~mm})$.We had only one case in whom the bar broke during the operation and it was repaired with screw and mini-plate. The cause of this complication was believed to be the narrowness of bar. So it was concluded that the height of the bar should be at least $4 \mathrm{~mm}$. There were no other complications during the procedure. And blood loss was minimal. No tooth damage was noted during surgery.

All of patients after operation had normal contouring in face. Follow up of patients was more than 12 years (mean 6.3 years). According to $\mathrm{X}$-rays and Cephalograms, there were no failure or relapse after operation. There was no bone resorption after the surgery (Figure 2(d)). The pedicle of chin bone was remained intact posteriorly, so there was no resorption of chin bone. The failure rate was zero. There were no relapses. We noted 4 - 8 months transient paresthesia and hypoesthesia in chin area of 28 cases, $62.2 \%$ of our patients. But there were not any permanent nerve paresthesia. And none of the patients needed secondary operation.

All of the patients had normalized face with normal proportions and dimensions. 37 patients were highly satisfied and evaluated the surgery as excellent and 8 patients evaluated it as good. Surgeons evaluated the results as 39 excellent and 6 good. 


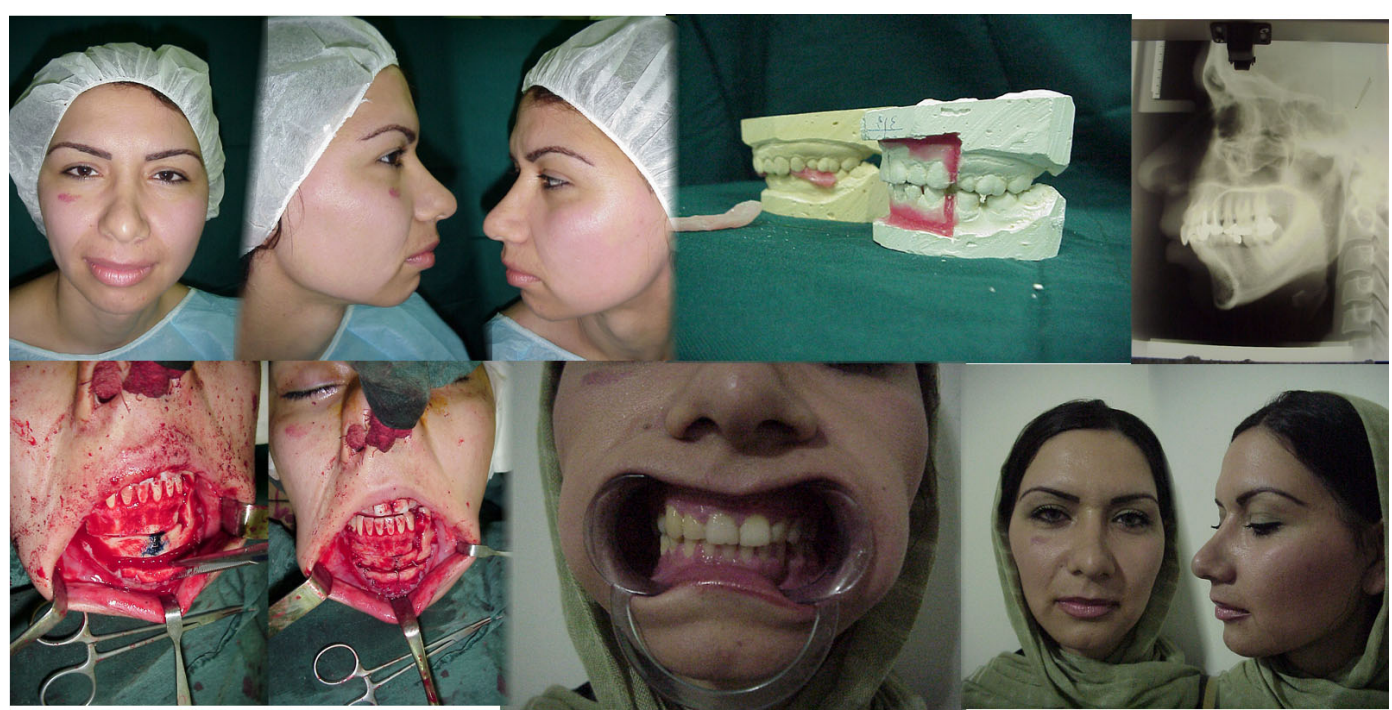

Figure 5. A lady with long middle third of face and retruded chin. The two lower left pictures show horizontal chin bar. Before surgery: Upper left three photos. After surgery: Lower right two photos.

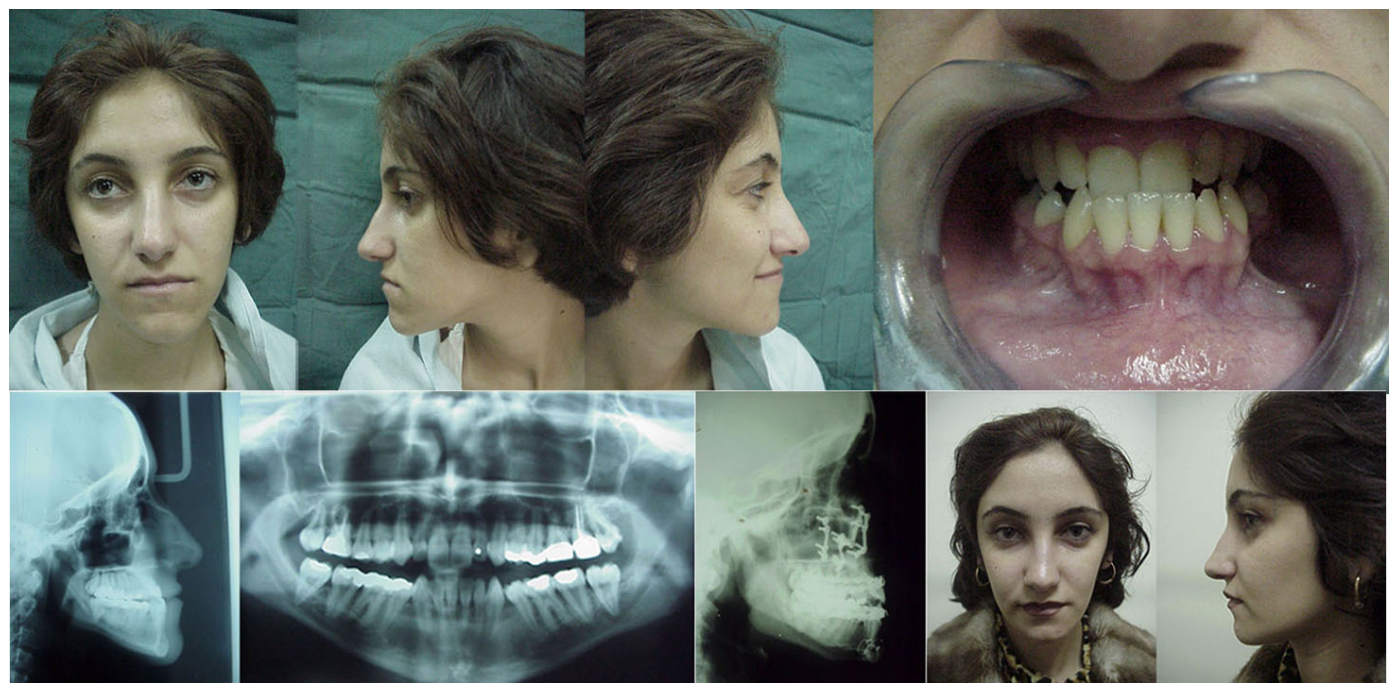

Figure 6. Long face, long chin and Class III malocclusion. Before surgery: Upper left three photos. After surgery: Lower right two photos.

\section{Discussion}

The long face patients need very careful evaluation and planning, and surgical reconstruction of these type faces needs very good experience, highly capable orthognatic surgeons and skillful technique in order to achieve a very good aesthetic result. Most of these patients have a bimax. Protrusion of dentoalveolar part and a long and retruded chin at the same time. These complex deformities need orthodontic treatment together with orthognatic surgery. Preoperative planning with cephalometry analysis and dental cast model is very important for this kind of orthognatic surgery [3]. Segmental osteotomy alone is insufficient to obtain maximum aesthetic improvement of mandibular contour 12. So, simultaneous correction of mandibular protrusion and mandibular bone excess in the vertical dimension and (in most of cases) correction of chin recession are required [4] [5]. In these patients merely bimax operation and body osteotomy or ramous sagittal splitting operation will not solve the whole problem. And this would lead to secondary complimentary operation or patients' dissatisfaction. Especially sensory disturbance in our method is much less noticeable than sagittal splitting osteotomy in which postoperative permanent decrease in sensitivity of the lower lip was reported to be as high as $20 \%$ - 45\% [6] [7]. The maxillary 
deformity is treated according to the type of deformity, but mandibular complex deformity needs complex and careful reconstruction.

Mandibular prognathism is defined by John Hunter as follows: "The lower jaw projecting too far forward so that the fore teeth pass before those of the upper jaw, therefore disfigurement and malocclusion are two of the main facial characteristics.” Other distinguishing features are the coexistence of Class III malocclusion, incomplete closure of lip, deviation of the midline, and decrease of labiomental fold and unfavorable aesthetic features [8] [9]. Generally the functional occlusion and balance facial harmony can be obtained by both surgical and orthodontic treatments. In general, mandibular prognathism is treated by the sagittal split ramus osteotomy (SSRO), OR, intraoral vertical ramus osteotomy (IVRO) and/or genioplasty [7] [10] [11].

In 1981, Bell reported some type of mandibular prognathism with relatively deficient chin and prominent lower lip and Class III malocclusion. He used intraoral vertical ramus osteotomy and advancement genioplasty with a near one-to-one ratio of soft tissue-to-osseous change in chin area [12]. In the same year, Scheideman et $a l$. have reported a good to excellent soft tissue change in this type of procedure and a ratio of 1:1 of soft tissue change for advancement of chin [13]. In 1996, Hoffman reviewed maxillary or mandibular surgery with genioplasty 5. He stated the effects of genioplasty in improving facial profile. And he mentioned surgical techniques for setback genioplasty. In 2002, Satoh, et al., have introduced a method of mandibular segmental osteotomy and chiseling out the protruding middle portion of protruding chin. 18 Asian patients were operated with this method with satisfactory aesthetic results [14]. In another report, Satoh, et al., have mentioned a segmental osteotomy in minor degree mandibular prognathism with double horizontal osteotomy and decortication of middle portion of it, and rapid aesthetic improvement and no intermaxillary fixation. They mentioned 4 - $5 \mathrm{~mm}$ setback of bone. And in their study no orthodontic treatments were required [4]. It is obvious that genioplasty is required in most of bimax. Surgeries and with a good selection of procedure, it will produce a better result and develop more beauty and harmony in the face.

Kolle's mandibular segmental osteotomy, with extraction of the bilateral first bicuspids, is usually used in cases of mild mandibular prognathism [6] [7]. And in this method, the premolar region alone is set back by segmental osteotomy. In our cases it was noted that such patients had two deformities: Mandibular premolar prognathism (or anterior part prognathism) and a retruded (and sometimes deviated) chin. It was obvious that two operations in the opposite directions should be done in order to have the best aesthetic results. Therefore, we performed two horizontal osteotomies in anterior mandible, producing a horizontal bar in between with 4 - 7 mm height. The protruding premolar region is set back and fixed by arch bar to other teeth, and the retruded chin is advanced and/ or elevated to have the best facial contour and profile. The lower segment usually will be fixed to the horizontal bar with wire (\#24 - \#30) (Figure 1(h), and Figure 3(h)) and sometimes with screws. Mean follow up of more than 6 years shows that the changes are stable. There are no bone resorption, relapse and significant permanent complications. This procedure can obtain a rapid aesthetic result. All of our patients were satisfied with the results and the bird beak deformity was treated very easily.

\section{Conclusion}

We recommend the horizontal chin bar technique in the patients with prognathism and a retruded (and/or deviated) chin.

\section{Acknowledgements}

The authors have no conflict of interest.

\section{References}

[1] Hoffman, G.R. and Moloney, F.B. (1996) The Stability of Facial Osteotomies, Chin Setback. Australian Dental Journal, 41, 178-183. http://dx.doi.org/10.1111/j.1834-7819.1996.tb04852.x

[2] Jackson, I., Munro, I.R., Salyer, K. and Witaker, L. (1982) Atlas of Craniomaxill of Acial Surgery. Mosby, St. Louis, 86-91.

[3] Parker, M.G., Lehman Jr., J.A. and Martin, D.F. (1989) Mandibular Prognathism in Orthognathic Surgery. Clinics in Plastic Surgery, 16, 677-679.

[4] Satoh, K., Tsukagoshi, T. and Shimizu, Y. (1996) Surgical Refinement of the Operative Procedure for a Minor Degree of Mandibular Prognathism. Plastic and Reconstructive Surgery, 98, 740-746. 
http://dx.doi.org/10.1097/00006534-199609001-00025

[5] Waring, D., Harrison, J. and Boyle, M. (2005) Three-Part Bi-Maxillary Osteotomy: A Case Report Involving Resorbable Plates. Journal of Orthodontics, 32, 75-84. http://dx.doi.org/10.1179/146531205225020934

[6] Bell, W.H. (1992) Modern Practice in Orthognathic and Reconstructive Surgery, Vol. 3. Saunders, Philadelphia, 21102169.

[7] Al-Bishri, A., Dahlberg, G., Barghash, Z., Rosenquist, J. and Sinzel, B. (2004) Incidence of Neurosensory Disturbance after Sagittal Split Osteotomy alone or Combined with Genioplasty. The British Journal of Oral \& Maxillofacial Surgery, 42, 105-111. http://dx.doi.org/10.1016/j.bjoms.2003.12.002

[8] Munro, I.R. (1982) Combining Facial Osteotomies for Aesthetic and Occlusal Change. Clinics in Plastic Surgery, 9, 457-458.

[9] Park, C.G., Yoo, J.W. and Park, I.C. (1994) Surgical Treatment of Mandibular Prognathism in Collaboration with Orthodontic Treatment in Korea. Aesthetic Plastic Surgery, 18, 407-412. http://dx.doi.org/10.1007/BF00451349

[10] Bell, W.H. (1981) Correction of Mandibular Prognathism by Mandibular Setback and Advancement Genioplasty. International Journal of Oral Surgery, 10, 221-229. http://dx.doi.org/10.1016/S0300-9785(81)80063-4

[11] Fischer, K., Von Konow, L. and Brattstrom, V. (2000) Open Bite: Stability after Bimaxillary Surgery-2-Year Treatment Outcome in 58 Patients. The European Journal of Orthodontics, 22, 711-718. http://dx.doi.org/10.1093/ejo/22.6.711

[12] Ong, H.B. (2001) Treatment of a Class III Anterior Open Bite Malocclusion: A Combined Orthodontic and Orthognathic Surgical Approach. Singapore Dental Journal, 24, 35-42.

[13] Scheideman, G.B., Legan, H.L. and Bell, W.H. (1981) Soft Tissue Changes with Combined Mandibular Setback and Advancement Genioplasty. Journal of Oral and Maxillofacial Surgery, 39, 505-509.

[14] Satoh, K., Tosa, Y. and Hosaka, Y.H. (2002) Mandibular Symphyseal Contouring in Mild Mandibular Prognathism. Aesthetic Plastic Surgery, 26, 401-406. http://dx.doi.org/10.1007/s00266-002-1014-1 
Scientific Research Publishing (SCIRP) is one of the largest Open Access journal publishers. It is currently publishing more than 200 open access, online, peer-reviewed journals covering a wide range of academic disciplines. SCIRP serves the worldwide academic communities and contributes to the progress and application of science with its publication.

Other selected journals from SCIRP are listed as below. Submit your manuscript to us via either submit@scirp.org or Online Submission Portal.
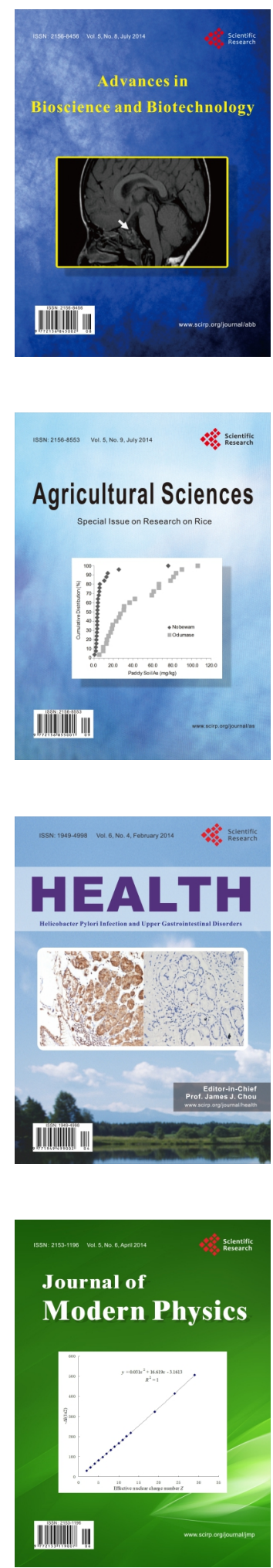
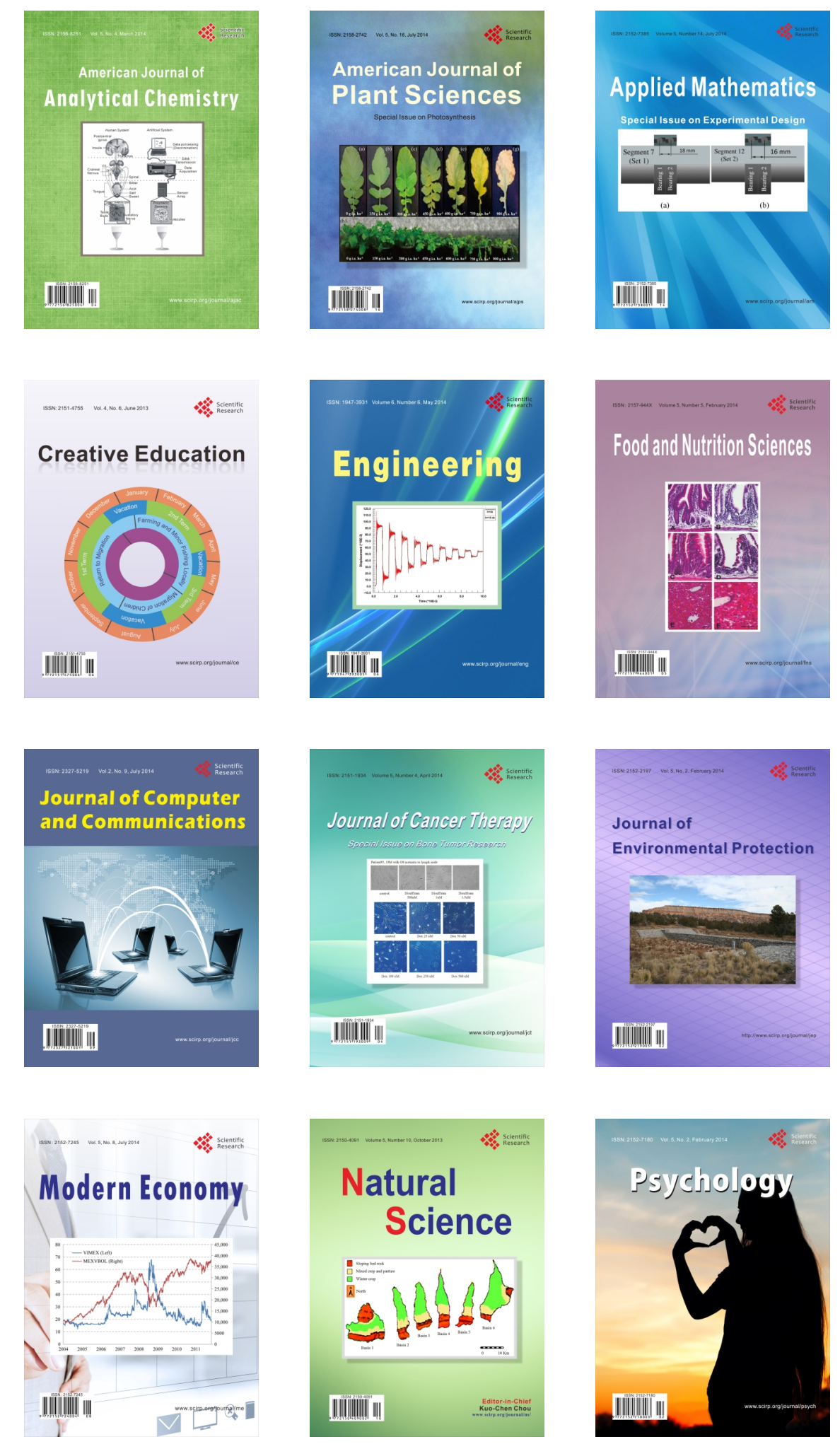